\title{
DISTRESS AND QUALITY OF LIFE AMONG TYPE II DIABETIC PATIENTS: ROLE OF PHYSICAL ACTIVITY
}

\author{
Devaraju Kadari', Gadiraju Padmaja², Binod Rajak ${ }^{3}$ \\ 1. Department of Psychology, Osmania University, India \\ 2. Health Psychology, University of Hyderabad, India \\ 3. School of Management Studies, University of Hyderabad, India
}

Correspondence: binodkumarhr@gmail.com

\begin{abstract}
This study measures the distress and Quality of Life (QOL) among people with type II diabetes in relation to physical exercise. The study was conducted using diabetic participants chosen from various hospitals, aerobic centres, playgrounds, and gyms in India. The participants were divided into two groups - group 1 comprising people who did not adopt physical activity as part of their diabetes management strategy and group 2 comprising people who engaged in physical activity. A non-equivalent control group design study was performed on both groups employing purposive sampling methods. Pearson $r$ showed that distress is negatively correlated with QoL among type II diabetics in both groups. Independent ttest indicated that participants in group 2 showed better QoL and lower levels of distress compared to their counterparts in group 1.
\end{abstract}

\section{KEYWORDS}

Distress, Quality of Life, Type II Diabetics, Physical Activity, India.

\section{INTRODUCTION}

Diabetes mellitus, a serious ailment of the 21 st century, is a predominant cause of morbidity and mortality and imposes a significant economic burden on the health care system worldwide. [1] Diabetes has been categorized as a chronic disease [2] and could be life-threatening because of the dangerous and inevitable complications that arise due to it. [3] The Director-General of WHO has declared diabetes to be a disease that no longer only affects rich nations but is becoming prevalent among developing and underdeveloped nations worldwide. [4]
Earlier studies have suggested that diabetes leads to many severe health conditions, including kidney failure, retinopathic blindness, lower-limb amputations, cardiovascular problems, and even death. Diabetes results from an imbalance in the body's ability to metabolize glucose, the body's primary source of energy, through disruptions in insulin action, the pancreatic hormone responsible for transporting glucose into cells for the release of energy through various biochemical cycles. 
Diabetes is of three types, viz., type I, type II and gestational diabetes. Type I diabetes caused by the pancreas' failure to produce insulin: due to faulty auto-immune response. Type II diabetes occurs due to insulin resistance of the cells in the body. In such condition, body cells cannot use insulin, and over time, the pancreas reduces the production of insulin, resulting in insulin deficiency. Type II diabetes is also known as "non-insulin dependent diabetes mellitus" or NIDDM. [5] Type II diabetes is the most commonly occurring type and accounts for $90 \%$ of total diabetic cases worldwide. Nearly 4.63 billion adults (20-79 years) have diabetes worldwide, and the number expected to exceed 7 billion by 2045. [6] It also projected that India would have about 57 million diabetic people by 2025 .

India is the diabetic capital with the fastest prevalence rate of type II diabetes. [7, 8, 9] This situation burdens individuals, their families, and the Indian healthcare system significantly. [10] The objectives of the study are to measure the distress and Quality of Life (QoL) among type II diabetic participants, analyse the relationship between distress and QoL of type II diabetic participants and compare the differences between distress and QoL in two groups of participants, one engaging in physical activity as a complementary management technique, and the other not following complementary management.

\section{REVIEW OF LITERATURE AND HYPOTHESES DEVELOPMENT}

\section{Type II diabetes and psychological outcomes (Diabetes-related Distress)}

Diabetes-related distress as the patient's concerns about his/her self-management of diabetes, perception of support, emotional burden, and access to quality health care. [11] The second version of Diabetes Attitudes, Wishes, and Needs (DAWN2) study was conducted in 17 countries through a global partnership initiative involving four continents. [12] The study showed that Diabetes-related Distress (DD) is found in all countries, with $44.6 \%$ of diabetes patients being affected by it. DD was also found to disrupt daily lives of patients through disturbed social interactions and emotional states. [13] Numerous studies have shown that anxiety, depression, distress and decreased QoL are the common psychological problems among people with type II diabetes. [14] Recent studies suggested that emotions play a significant role in an individual's life. [15] Researchers have also shown that the mere presence of DD as a comorbid condition is likely to decrease QoL among type II diabetics. [16] High DD has been shown to result in poor glycaemic control $[17,18]$ and psychological distress might also hamper QoL. [19, 20, 21]

\section{Type II diabetes and quality of life}

World Health Organization defines QoL as an "individual's perception of their position in life in the context of the culture and value systems in which they live and about their expectations, standards, concerns and goals". [22] QoL among people with diabetes provides a varied perception that encompasses the emotional, physical, and social functioning. [23] Type II diabetes gradually affects an individual's physical, mental, spiritual, and sociocultural dimensions, which compromise patients' QoL. Generally, patients report low QoL levels when they are suffering from one or more than one comorbid condition, i.e., diseases like type II diabetes, cardiovascular diseases and cancer are more strongly related to poor QoL than other chronic diseases. [24] The previous study suggested that diabetic patients and QoL negatively associated with each other. [25] The QoL of diabetics could be negatively affected by complications such as obesity, hypoglycaemia, depression, and ageing. [26] A study has shown that patients of type II diabetes have poor QoL due to depression. [27]

\section{Physical activity (PA) and its benefits for type II diabetics}

Recent studies have shown that regular physical exercise is associated with better QoL among type II diabetes patients. $[28,29]$ Health and quality of life outcomes impair quality of life in type II diabetes mellitus. [30] Physical activity categorizes into several types: walking, resistance exercise, flexible exercise, aerobic exercise, musclestrengthening, bone-strengthening, and stretching. [31] A combination of exercises such as walking, dancing, and weightlifting on most days of the week can help control blood glucose levels. Regular physical activity helps lower blood glucose levels with type II diabetes. [32] Better social life and physical activity have higher satisfaction in men than women. [33] The promotion and adoption of lifestyle changes such as healthy diet, regular physical activities, reducing smoking and maintaining healthy body weight have universally acknowledged acceptable diabetes management practices. It has also shown that communitywide approaches that facilitate physical activity could reduce chronic problems of diabetics in the community. [34] Numerous studies that correlate exercise and QoL have that people who engaged in more physical activity 
have better QoL and overall health than those who do not engage in physical exercise. [35]

The American Diabetes Federation (ADA) suggests that patients with type II diabetes must engage in at least 150 minutes of any physical activity such as walking, running, cycling, swimming, resistance training, stretching, and strengthening every week, or a minimum 90 minutes of energetic aerobic related exercises per week. [36] An earlier study has suggested that physical activity related exercises must prescribed to all people with diabetes as part of their glycaemic control management. [37] Healthy lifestyle interventions must include regular physical activity, brisk walking, or light resistance exercises. [38, 39, 40] Regular physical activities like walking 10,000 steps a day also appear to help prevent and manage type II diabetes. [41] Literature suggests the reducing sedentary time improves the glucose control in type II Diabetic patients. [42] Following a healthy lifestyle reduces the risk of type ॥ diabetics. [43] Recent research revealed that PA significantly affects Diabetics type II patients. [44, 45] Walking ten thousand steps helps improve people with diabetes type II patients. [46]

Given the proliferation of type II diabetes worldwide, there is a need to understand the various parameters related to this illness. QoL plays an essential role in health, significantly because diabetic distress can affect type \| diabetic patients' health. However, literature linking type II diabetes and distress, QoL is scarce, more so in the Indian setting. This study has conceptualized to find the links between these three variables and proposed following hypotheses.

H1- There is a significant difference between groupl (participants not engaging in any physical activity) and group 2 (participants engaging in physical activity as a complementary diabetes management technique) in quality of life and distress.

H2- There is an association between distress and QoL of patients with type II diabetes.

\section{METHODOLOGY}

\section{Plan and design}

The present study used a non-equivalent control group design. [47] The participants divided into two groups. "A" was our control group 1, in which participants did not adopt any complementary management technique involving physical activity. "B" was our group 2, in which, participants followed a complementary management technique of physical activity such as walking, aerobic activity, resistance exercises and other strengthening exercises. The participants remained unaware of their categorization into two different groups, and English is the language in which the tools administered. Results were analysed using IBM SPSS 20. The independent variable was the complementary management technique used, i.e., walking, aerobic activity, resistance exercises and other strengthening exercises, and the dependent variables were distress and quality of life.

\section{Participants}

The purposive sampling method was used for a sample of 200 people diagnosed with type II diabetes. [48] The sample comprised 114 men and 86 women with type II diabetes since the last six months-one hundred participants placed in each group. The participants of groupl were the out-patients from various hospitals and playgrounds, gym centres and aerobic centres in south India. People diagnosed with type II diabetes adhering to medication in group 1 and adhering to medication and physical activity in group 2. The participants were in the age group of 29 - 80 years. The mean score of age and standard deviation score for group 1 were 60.27 and 7.99; those for group 2 were 61.20 and 9.79; those for the overall sample were 60.74 and 8.93, respectively. Group 1 participants were on medication alone, while group 2 participants in addition to medication, following a physical exercise regimen for at least six months. Physical exercises included walking, running, cycling, swimming, resistance training, stretching, and strengthening and aerobic exercise. Type II diabetic participants following alternative forms of management techniques to control their diabetes like yoga and faith-based yoga are excluded from the study.

\section{Measurement tools}

The Diabetes Distress Scale, English (DDS17E) comprising 17 items were used to measure the distress among Type ॥ diabetics. [49] Each question score on a 1 to 6 scale range, where 1 indicated 'not a problem' and 6 denoted 'serious problem'. This scale measured four dimensions of distress, namely Emotional Distress (ED) (5 items), Physician-related Distress (PD) (4 items), Regimen-related Distress (RD) (5 items) and Interpersonal Distress (ID) (3 items). Scores range from 17 to 102. Diabetes 39 scale consisting of 39 items and two overall rating scales, was used to measure Type ॥ 
diabetic participants' QoL. [50] It is a multidimensional scale that assesses five domains of QoL including diabetes control (12 items), energy and mobility (15 items), anxiety and worry (4 items), social burden (5 items) and sexual functioning ( 3 items). The 39 items were measured using a five-point Likert scale, and score ranged from $39-273$. Higher the score, lower is the quality of life and vice versa. The reliability ranged from 0.82 to 0.93 .

\section{RESULTS}

The analysis uses the correlation to understand the relationship between QoL and distress and t-test, to analyse the differences between groupl and group 2 in QoL and distress. The results analyse as total distress and total QoL along with their dimensions. Table 1 shows that the participants of the two groups differed significantly in the level of distress. The participants in group 2 had lower diabetes-related distress $(M=24.70, S D=8.94, \dagger(198)=16.76$, $p<.001$, Cohen's $d=2.37$ ) compared to the participants in group 1 ( $M=48.06, S D=10.68)$. Significant differences were found between the two groups in all four dimensions of distress with the following data: emotional distress, († (198) $=15.27, p<.01$, Cohen's $d=2.16)$, physician-related distress, ( $\dagger$ (198) $=9.25, p<.01$, Cohen's $d=1.33$ ), regimen-related distress, $(\dagger(198)=16.96, p<.01$, Cohen's $d=2.42)$, and interpersonal distress, $(\dagger(198)=11.09, p<.01$, Cohen's $d=1.58$ ). Table 2 shows that the participants of the two groups differed significantly in their quality of life. The participants in group 2 had better $Q \circ L(M=12.14, S D=8.72)$, $\dagger(198)=19.13, p<.01$, Cohen's $d=2.70$ than the participants in group $1(M=40.29, S D=11.84)$. Significant differences can be seen between the two groups on five dimensions of quality of life.

TABLE 1, MEAN (M), STANDARD DEVIATION (SD) AND T-SCORES OF GROUP 1 AND GROUP 2 WITH RESPECT DIABETIC DISTRESS AND ITS DOMAINS

\begin{tabular}{|l|l|l|l|l|l|l|}
\hline \multirow{2}{*}{ VARIABLES } & \multicolumn{2}{|l}{ GROUP } & \multicolumn{2}{l|}{ GROUP 2 } & T (198) & COHEN'S D \\
\cline { 2 - 8 } & Mean & SD & Mean & SD & & \\
\hline 1. Distress total & 48.06 & 10.68 & 24.7 & 8.94 & $16.76^{* *}$ & 2.37 \\
\hline a. Emotional distress & 3.45 & 0.82 & 1.72 & 0.78 & $15.27^{* *}$ & 2.16 \\
\hline b. Physician related distress & 1.86 & 0.58 & 1.2 & 0.39 & $9.25^{* *}$ & 1.33 \\
\hline c. Regimen related distress & 3.25 & 0.81 & 1.49 & 0.63 & $16.96^{* *}$ & 2.42 \\
\hline d. Interpersonal distress & 2.36 & 0.85 & 1.26 & 0.49 & $11.09^{* *}$ & 1.58 \\
\hline
\end{tabular}

** $p<.01$, M-mean, SD- standard deviation

TABLE 2 MEAN (M), STANDARD DEVIATION (SD) AND T-SCORES OF GROUP 1 AND GROUP 2 REGARDING DIABETES QOL AND ITS DOMAINS

\begin{tabular}{|c|l|l|l|l|l|l|}
\hline \multirow{2}{*}{ VARIABLES } & \multicolumn{2}{|l|}{ GROUP 1 } & \multicolumn{2}{l|}{ GROUP 2 } & \multirow{2}{*}{ T (198) } & \multirow{2}{*}{ COHEN'S D } \\
\cline { 2 - 6 } & Mean & SD & Mean & SD & & \\
\hline 2. QoL total & 40.29 & 11.84 & 12.14 & 8.72 & $19.13^{* *}$ & 2.7 \\
\hline a. Energy and mobility & 42.84 & 12.04 & 14.66 & 9.09 & $18.07^{* *}$ & 2.57 \\
\hline b. Diabetes control & 37.8 & 12.18 & 9.17 & 10.54 & $17.27^{* *}$ & 2.51 \\
\hline c. Anxiety and worry & 40.04 & 14.01 & 11.92 & 11.8 & $15.35^{* *}$ & 2.17 \\
\hline d. Sexual behaviour & 50.17 & 19.09 & 21.72 & 17.01 & $11.12^{* *}$ & 1.57 \\
\hline e. Social burden & 34.83 & 15.17 & 6.17 & 8.22 & $16.60^{* *}$ & 2.34 \\
\hline
\end{tabular}

** $\mathrm{p}<.01, \mathrm{M}$-mean, SD- standard deviation 
Distribution of distress scores in group 1 and group 2 participants with type II diabetes

The frequency distribution of distress scores of the 100 participants in group 1, shown in figure 1. The scores of the participants ranged from 10 to 75 . The mean and standard deviation scores were 48.06 and 10.68, respectively. Figure 1 shows the scores of distresses of the 100 participants in group 2. The scores ranged from 15 to 50 . The mean and standard deviation scores were 24.70 and 8.94, respectively. The distribution of QoL scores for 100 participants in group 1 (figure 1) wherein the scores ranged from 5 to 76 . The mean and standard deviation scores were 40.29 and 11.84, respectively. The frequency distribution of QoL scores of group 2 participants (figure 2) in which, the scores ranged from 0 to 40 . The mean and standard deviation scores were 12.14 and 8.73, respectively. The Bar graph shows that the participants in two groups varied in their mean scores on distress and QoL (Figure 3). We can see that the participants in group 1 have higher distress than group 2 participants. We can also see that participants in group 1 had poor QoL than group 2 participants.

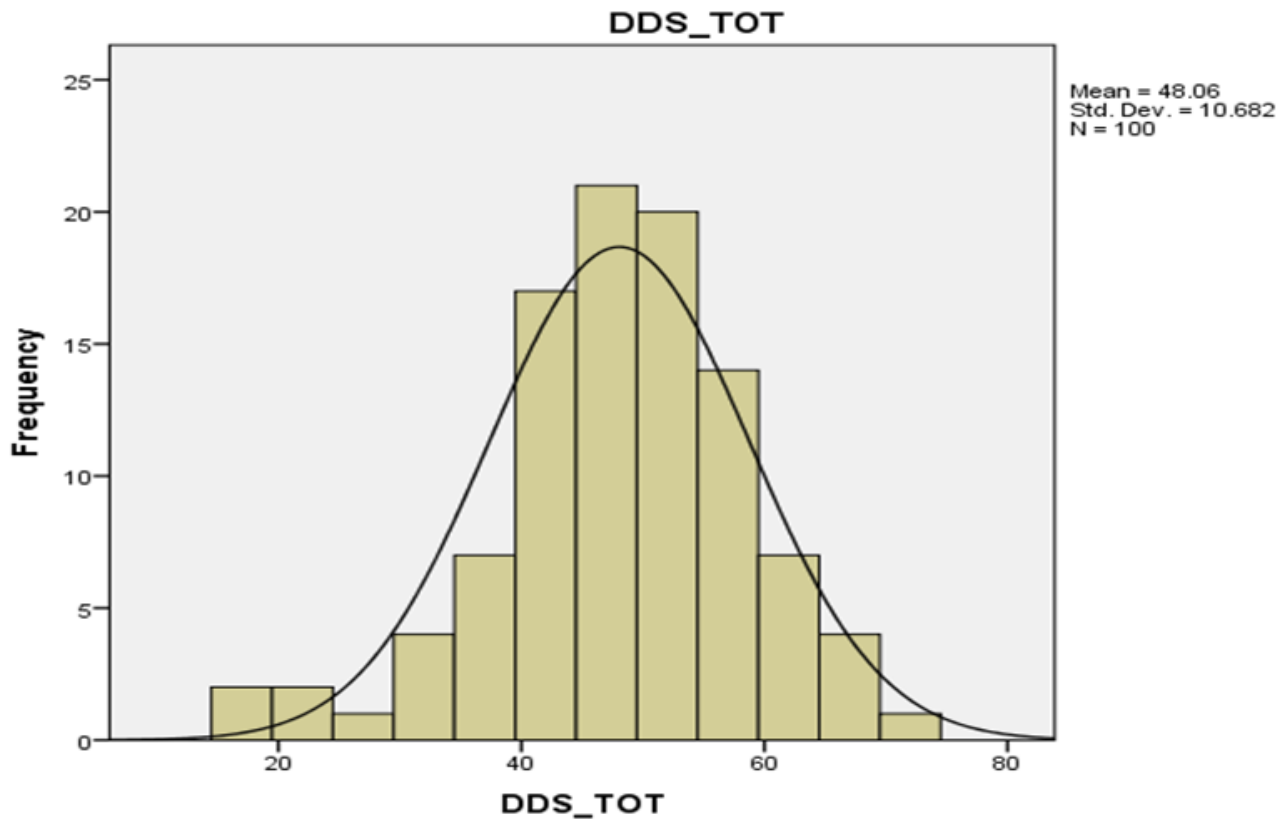

FIGURE 2.2: FREQUENCY DISTRIBUTION OF THE DISTRESS SCORES OF PARTICIPANTS IN GROUP $2(M=24.70, S D=8.94)$

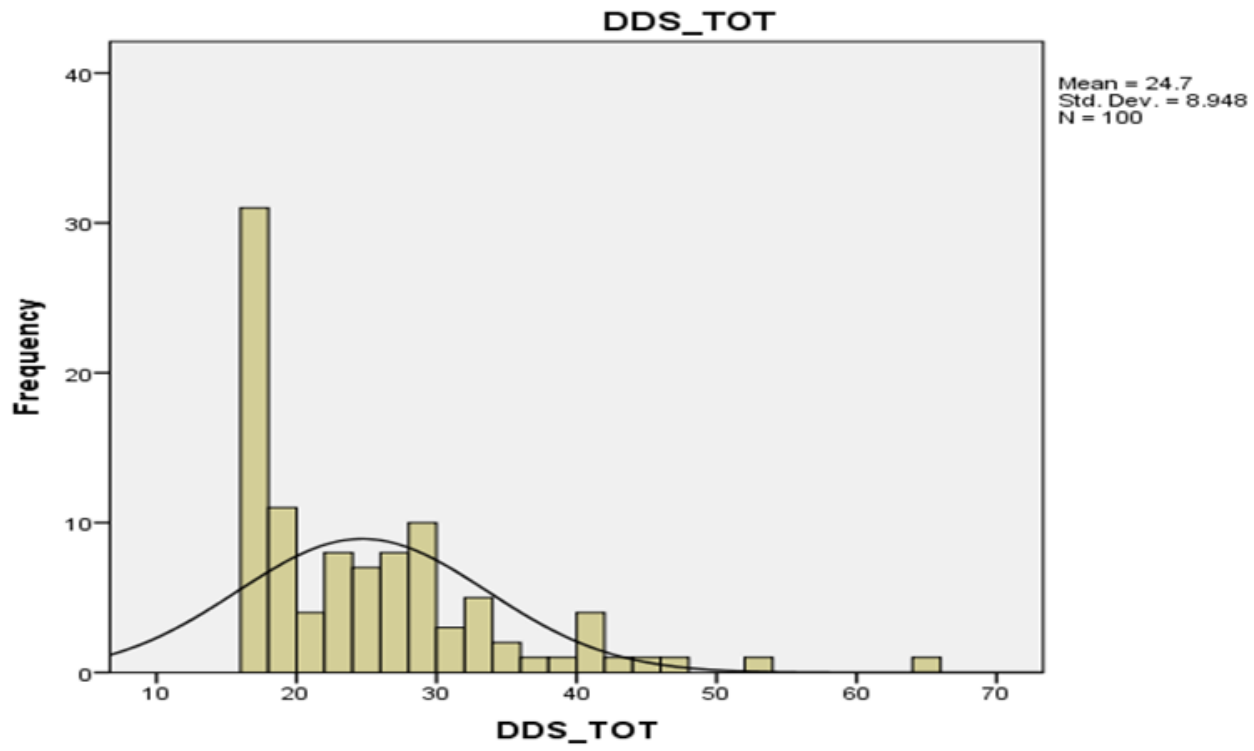




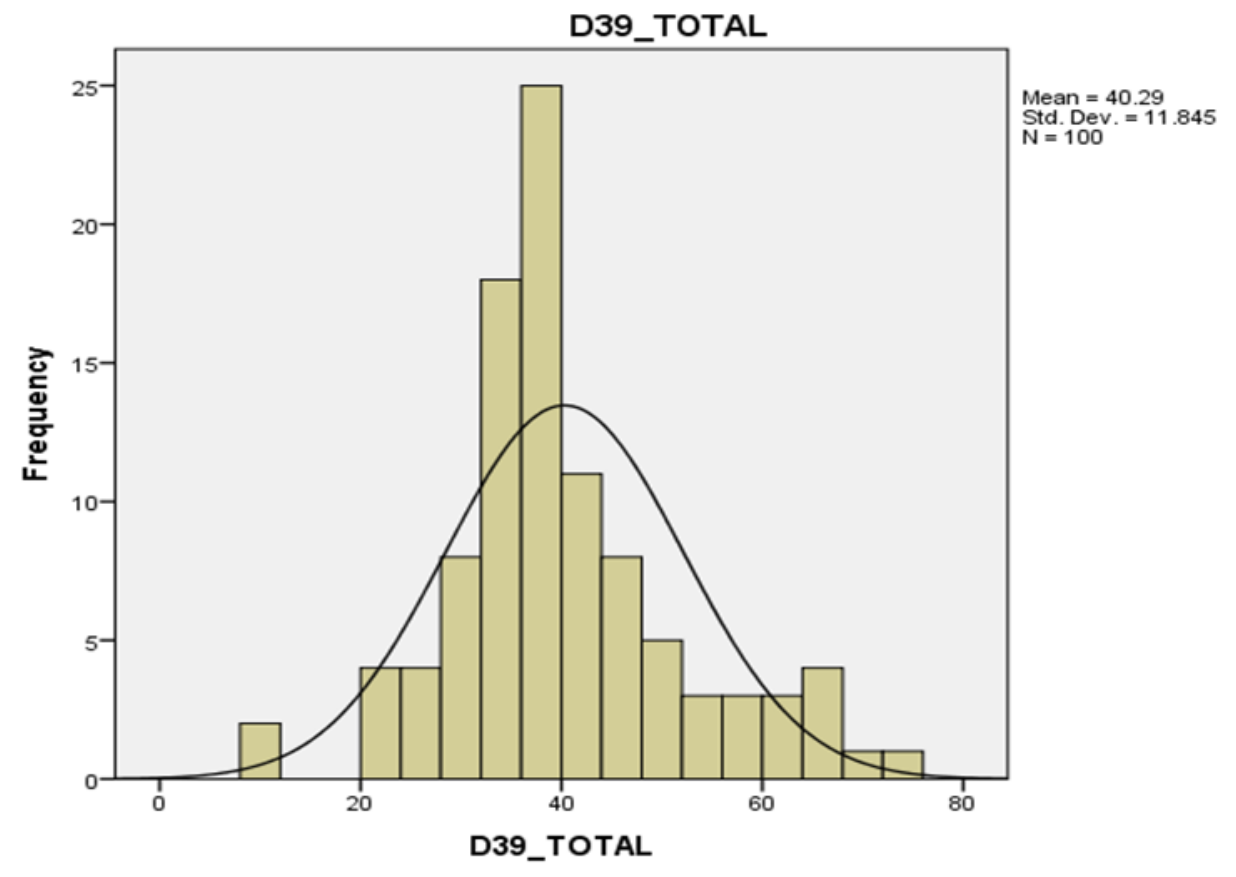

FIGURE 2.2: FREQUENCY DISTRIBUTION OF THE QOL SCORES OF PARTICIPANTS IN GROUP $2(M=12.14, S D=8.73)$

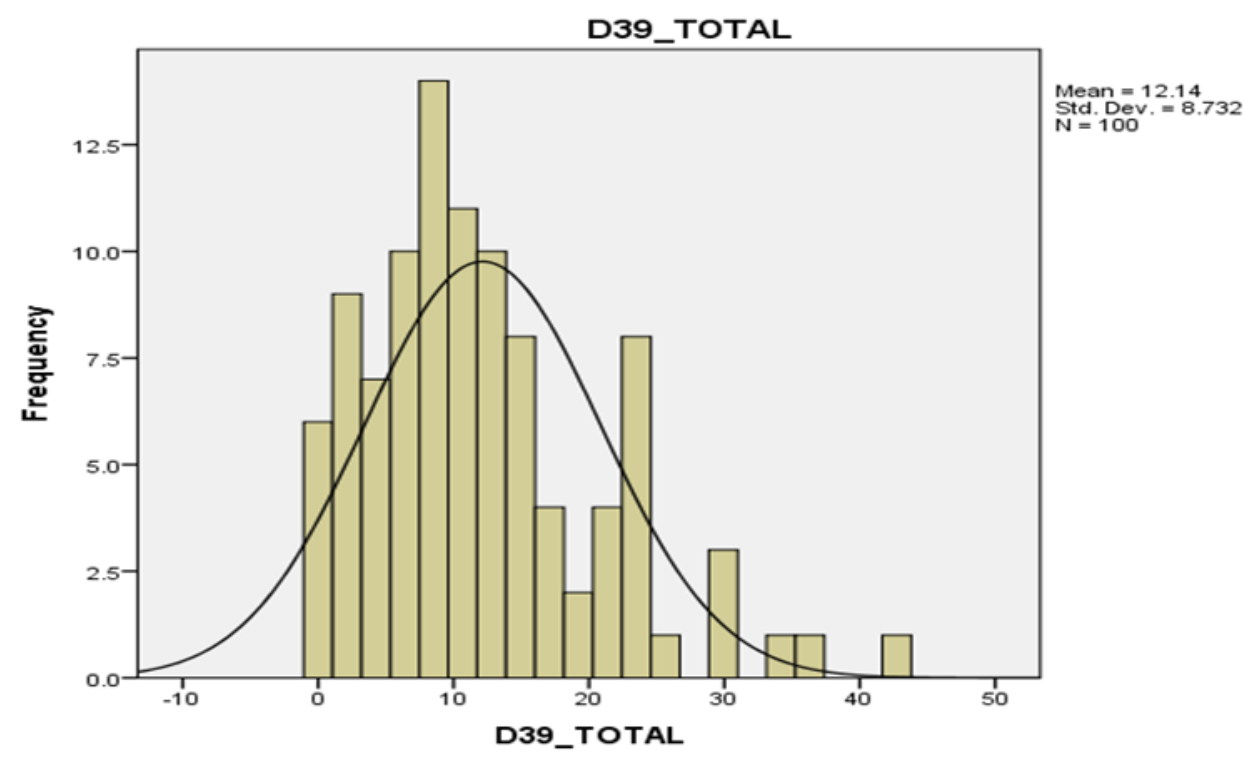




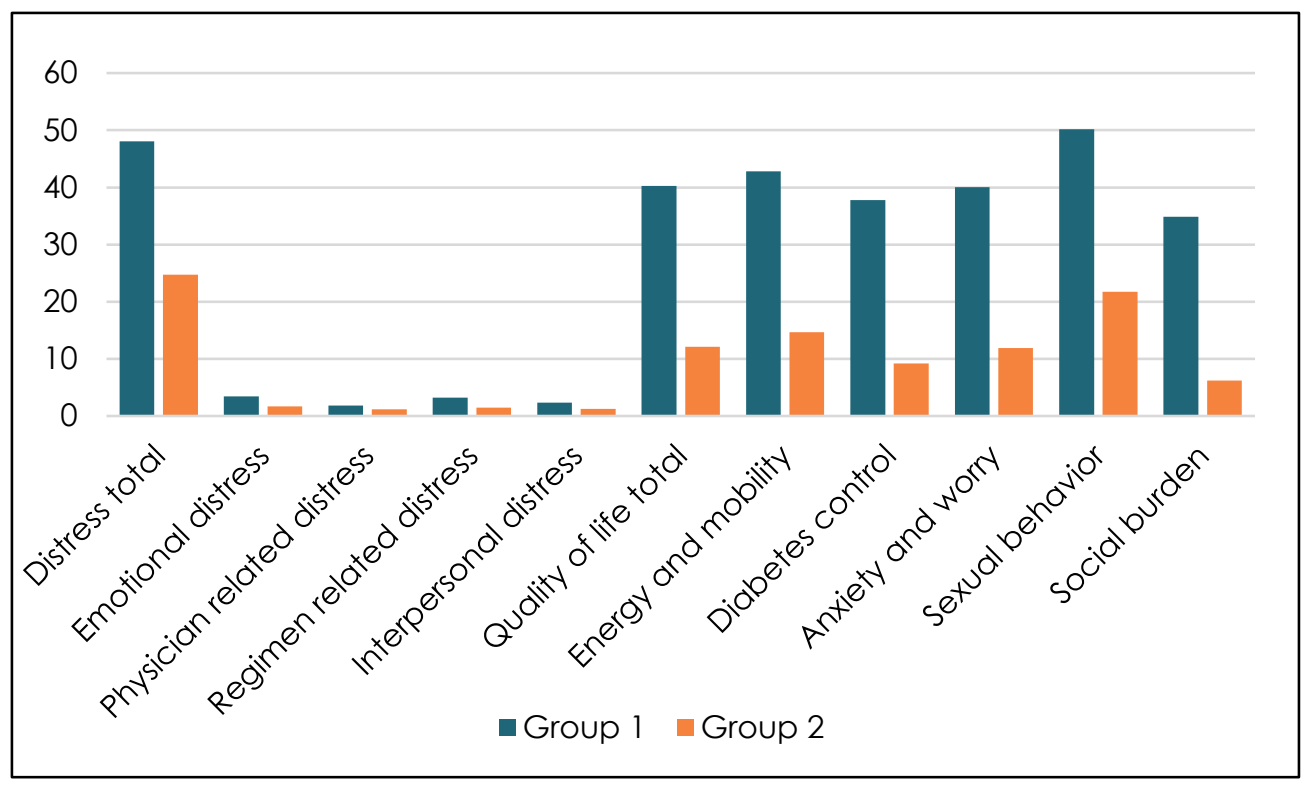

TABLE 3: THE INTERCORRELATION BETWEEN DISTRESS AND QUALITY OF LIFE

\begin{tabular}{|l|l|l|l|l|l|l|l|l|l|l|l|}
\hline & TD & ED & PD & RD & ID & TQOL & EM & DC & AW & SF & SB \\
\hline TD & - & $.93^{* *}$ & $.78^{* *}$ & $.93^{* *}$ & $.74^{* *}$ & $.73^{* *}$ & $.64^{* *}$ & $.75^{* *}$ & $.51^{* *}$ & $.28^{* *}$ & $.50^{* *}$ \\
\hline ED & & - & $.59^{* *}$ & $.82^{* *}$ & $.55^{* *}$ & $.68^{* *}$ & $.60^{* *}$ & $.74^{* *}$ & $.47^{* *}$ & $.20^{*}$ & $.41^{* *}$ \\
\hline PD & & & - & $.64^{* *}$ & $.68^{* *}$ & $.59^{* *}$ & $.49^{* *}$ & $.62^{* *}$ & $.41^{* *}$ & $.24^{*}$ & $.47^{* *}$ \\
\hline RD & & & - & $.59^{* *}$ & $.67^{* *}$ & $.59^{* *}$ & $.65^{* *}$ & $.45^{* *}$ & $.38^{* *}$ & $.44^{* *}$ \\
\hline ID & & & & & - & $.53^{* *}$ & $.44^{* *}$ & $.54^{* *}$ & $.43^{* *}$ & 0.11 & $.49^{* *}$ \\
\hline EM & & & & & & - & $.89^{* *}$ & $.92^{* *}$ & $.75^{* *}$ & $.53^{* *}$ & $.72^{* *}$ \\
\hline DC & & & & & & & - & $.72^{* *}$ & $.56^{* *}$ & $.39^{* *}$ & $.44^{* *}$ \\
\hline AW & & & & & & & & & $.68^{* *}$ & $.34^{* *}$ & $.72^{* *}$ \\
\hline SF & & & & & & & & & & $.27^{* *}$ & $.57^{* *}$ \\
\hline SB & & & & & & & & & & & $.37^{* *}$ \\
\hline
\end{tabular}

Note: $T D=$ Total Distress, $E B=$ Emotional Burden, $P D=$ Physician-related Distress, $R D=$ Regimen-related Distress, ID $=$ Interpersonal Distress, $T Q O L=$ Total Quality of Life, $E M=$ Energy \& Mobility, $D C=$ Diabetes Control, $A W=$ Anxiety \& Worry, $S F=$ Sexual Functioning and $S B=S O c i a l$ Burden. ${ }^{* *} p<.01,{ }^{*} p<.05$.

\section{DISCUSSION}

This study's first objective was to measure the distress and QoL among type II diabetic participants about their physical exercise. The study showed that group 2 experienced lower levels of distress and had better QoL than those of group 1. The study's second objective was to analyse the association between distress and QoL in type ॥ diabetic participants. Results analysed through Pearson ( $r$ ), indicated a negative correlation between distress and quality of life. Based on the scores alone, the present study's result proves a positive correlation between the 
scores of distress and quality of life. There is thus sufficient evidence that distress and QoL among type II diabetic participants are negatively correlated. This study's third objective was to compare the difference between distress and QoL of group 1 and group 2 participants. Results analysed through t-test showed the significant relationship between low level of distress and high QoL regarding their dimensions in group 2. [51]

The results of this study suggest that adherence to daily physical activity plays a critical role in the effective management of type II diabetes, which is consistent with observations from recent studies on the association between physical activity and diabetes management. [52, $53,54]$ Walking for at least 30 minutes every day was shown to reduce the risk of type II diabetes by approximately $50 \%$. [55] Previous research suggests that an intense PA leads to critical problems, so a person with type II diabetes can safely perform PA. [56] On the contrary to this, lack of infrastructure, and physical constraints were the factors that acted as barriers to physical activity among older adults. [57]

In the correlation table for group 2, when we move across the distress, QoL and their dimensions, both variables and their dimensions have significant relationships with each other; except for two dimensions - physician-related distress and regimen related distress. These two dimensions, however, had a significant relationship with the QoL dimension, sexual functioning. On the other hand, interpersonal distress was not a significant association with sexual functioning; because many of the participants were older adults who already reached menopause and andropause and may have associated with other significant old age problems. In group 2, QoL and all its dimensions had significant relationships with distress but not group 1. The lack of significance level could be attributed to lack of physical activity and various other significant factors. With these observations, we can conclude that group 2 have better QoL than participants in group 1.

\section{IMPLICATIONS OF THE STUDY}

The study proves the physiological responses to physical activity and their role in lowering distress and improving QoL regarding type II diabetic participants. These findings allow psychologists (especially health psychologists) to confidentially design interventions that include physical activity, to minimize the distress and improve the QoL in type II diabetic patients. The study also indicates specific physical activity techniques that are convenient and manageable for patients with type II diabetes. This study also points out the need for the healthcare professionals and policymakers to take necessary steps in designing effectual interventions for the improvement of overall health aspects of type II diabetic patients. The government must design interventions related to various physical activity techniques on type II diabetics. This intervention should be done through various diabetic prevention programs under the surveillance of National Health Schemes.

\section{CONCLUSION}

This study shows the importance of physical activity among people with type II diabetes and proves that physical exercise and psychological relaxation could improve patients' QoL. PA recommendations should tailor to meet the specific needs of people with type II diabetes. [58] The psychological outcomes can see in the present study through the low scores on the scale of diabetes distress and high QoL scores associated with physical activity. Several unhealthy behavioural practices of people with type ॥ diabetes leads to various psychological disturbance. Some of the PD are decreased QoL in type II diabetic participants and thus stressed that physical activity is imperative to diabetes patients to reduce distress and improve quality of life.

\section{LIMITATION AND FUTURE SCOPE}

The sample size is too small to generalize the findings and is also geographically restricted to India's southern part. Future studies may include a larger sample size with a random sample. Future studies can study the effects of preand post-intervention methods. If the medical intervention combined with psychophysiological interventions, it fetches better results in the overall QoL of type II diabetic participants. The study results showed that distress correlates negatively with QoL among type II diabetics in both groups, which demands the need for interventions, especially managing type II diabetes through physical activity.

\section{References}

1. Zhang P, Zhang X, Brown J, Vistisen D, Sicree R, Shaw J, Nichols $G$. Global healthcare expenditure on diabetes for 2010 and 2030. Diabetes research and clinical practice. 2010 Mar 1;87(3):293-301. 
2. Tabish SA. Is diabetes becoming the biggest epidemic of the twenty-first century? International Journal of health sciences. $2007 \mathrm{Jul} ; 1(2): \mathrm{V}$.

3. Doshi KB, Kashyap SR, Brennan DM, Hoar BM, Cho L, Hoogwerf BJ. All-cause mortality risk predictors in a preventive cardiology clinic cohort-examining diabetes and individual metabolic syndrome criteria: a PRECIS database study. Diabetes, Obesity and Metabolism. 2009 Feb; 11 (2):102-8.

4. World Health Organization. Global report on diabetes: executive summary. World Health Organization; 2016.

5. Fulton-Kehoe D, Hamman RF, Baxter J, Marshall J. A case-control study of physical activity and non-insulin dependent diabetes mellitus (NIDDM): the San Luis Valley Diabetes Study. Annals of epidemiology. 2001 Jul 1:1 1 (5):320-7.

6. IDF Diabetes Atlas (9th ed.), International Diabetes Federation, Brussels, Belgium (2019)

7. John R, Pise S, Chaudhari L, Deshpande PR. Evaluation of quality of life in type 2 diabetes mellitus patients using quality of life instrument for indian diabetic patients: A cross-sectional study. Journal of mid-life health. 2019 Apr;10(2):81.

8. World Health Organization. Global report on diabetes: executive summary. 2016.

9. Manjunath K, Christopher P, Gopichandran V, Rakesh PS, George K, Prasad JH. Quality of life of a patient with type 2 diabetes: A cross-sectional study in Rural South India. Journal of family medicine and primary care. 2014 Oct;3(4):396.

10. Wild S, Roglic G, Green A, Sicree R, King H. Global prevalence of diabetes: estimates for the year 2000 and projections for 2030. Diabetes care. 2004 May 1;27(5):1047-53.

11. Fisher L, Glasgow RE, Mullan JT, Skaff MM, Polonsky WH. Development of a brief diabetes distress screening instrument. The Annals of Family Medicine. 2008 May $1 ; 6(3): 246-52$.

12. Peyrot M, Burns KK, Davies M, Forbes A, Hermanns N, Holt R, Kalra S, Nicolucci A, Pouwer F, Wens J, Willaing I. Diabetes Attitudes Wishes and Needs 2 (DAWN2): a multinational, multi-stakeholder study of psychosocial issues in diabetes and person-centred diabetes care. Diabetes research and clinical practice. 2013 Feb $1 ; 99(2): 174-84$.

13. Holt RI, Nicolucci A, Burns KK, Escalante M, Forbes A, Hermanns N, Kalra S, Massi-Benedetti M, Mayorov A,
Meneendez-Torre 10 E, Munrol 1 N. Educational and Psychological Issues Diabetes Attitudes, Wishes and Needs second study (DAWN2TM): Cross-national comparisons on barriers and resources for optimal care-healthcare professional perspective. Diabet. Med. 2013;30:789-98.

14. Musselman DL, Ziemer DC, McNutt MD, Seay JS, Royster EB, Larsen B, Barham T, Brown AR, Vogel OL, Phillips LS, Harvey PD. Depression, deficits in functional capacity, and impaired glycemic control in urban African Americans with type 2 diabetes. Journal of psychiatric research. 2014 May 1;52:21-7.

15. Rajak, B. K., Singh, P., \& Pavneet Kaur. An explorative research on Emotional labour: a study of service industry. An International Multidiscipliary Quarterly Research Journal. 2019 Jan; 8(1): 23-30.

16. Beverly EA. Stressing the Importance of Diabetes Distress: a Comment on Baek et al. Annals of Behavioral Medicine. 2014 Oct 1;48(2):137-9.

17. Jeon CY, Lokken RP, Hu FB, Van Dam RM. Physical activity of moderate intensity and risk of type 2 diabetes: a systematic review. Diabetes care. 2007 Mar 1;30(3):744-52.

18. Hernandez L, Leutwyler $H$, Cataldo J, Kanaya A, Swislocki A, Chesla C. Symptom experience of older adults with type 2 diabetes and diabetes-related distress. Nursing research. 2019 Sep 1;68(5):374-82.

19. Pouwer F. Should we screen for emotional distress in type 2 diabetes mellitus?. Nature Reviews Endocrinology. 2009 Dec;5(12):665. https://doi.org/10.1038/nrendo.2009.214

20. Jeong M, Reifsnider E. Associations of diabetes-related distress and depressive symptoms with glycemic control in Korean americans with type 2 diabetes. The Diabetes Educator. 2018 Dec;44(6):531-40.

21. Hernandez L, Leutwyler $\mathrm{H}$, Cataldo J, Kanaya A, Swislocki A, Chesla C. Symptom experience of older adults with type 2 diabetes and diabetes-related distress. Nursing research. 2019 Sep 1;68(5):374-82.

22. Whoqol Group. The World Health Organization quality of life assessment (WHOQOL): position paper from the World Health Organization. Social science \& medicine. 1995 Nov 1;41(10):1403-9.

23. Alghnam S, Palta M, Remington PL, Mullahy J, Durkin MS. The association between motor vehicle injuries and health-related quality of life: a longitudinal study 
of a population-based sample in the United States. Quality of life research. 2014 Feb;23(1):119-27.

24. Fortin M, Bravo G, Hudon C, Lapointe L, Almirall J, Dubois MF, Vanasse A. Relationship between multimorbidity and health-related quality of life of patients in primary care. Quality of life research. 2006 Feb; 15(1):83-91.

25. Manjunath K, Christopher P, Gopichandran V, Rakesh PS, George K, Prasad JH. Quality of life of a patient with type 2 diabetes: A cross-sectional study in Rural South India. Journal of family medicine and primary care. 2014 Oct;3(4):396.

26. Ali S, Stone M, Skinner TC, Robertson N, Davies M, Khunti K. The association between depression and health-related quality of life in people with type 2 diabetes: a systematic literature review.

Diabetes/metabolism research and reviews. 2010 Feb;26(2):75-89.

27. Zurita-Cruz JN, Manuel-Apolinar L, Arellano-Flores ML, Gutierrez-Gonzalez A, Najera-Ahumada AG, CisnerosGonzalez N. Health and quality of life outcomes impairment of quality of life in type 2 diabetes mellitus: a cross- sectional study. Health and quality of life outcomes. 2018 Dec; 16 (1): 1-7.

28. Jing $X$, Chen J, Dong Y, Han D, Zhao H, Wang X, Gao F, Li C, Cui Z, Liu Y, Ma J. Related factors of quality of life of type 2 diabetes patients: a systematic review and meta-analysis. Health and quality of life outcomes. 2018 Dec;16(1):1-4.

29. Zurita-Cruz JN, Manuel-Apolinar L, Arellano-Flores ML, Gutierrez-Gonzalez A, Najera-Ahumada AG, CisnerosGonzalez N. Health and quality of life outcomes impairment of quality of life in type 2 diabetes mellitus: a cross- sectional study. Health and quality of life outcomes. 2018 Dec; 16 (1): 1-7.

30. Jing X, Chen J, Dong Y, Han D, Zhao H, Wang X, Gao F, Li C, Cui Z, Liu Y, Ma J. Related factors of quality of life of type 2 diabetes patients: a systematic review and meta-analysis. Health and quality of life outcomes. 2018 Dec;16(1):1-4.

31. Vezina JW, Der Ananian CA, Greenberg E, Kurka J. Sociodemographic Correlates of MeetingUS Department of Health and Human Services Musclestrengthening Recommendations in MiddleAged and OlderAdults. Prev Chronic Dis 2014;11:140007. DOI:

http://dx.doi.org/10.5888/pcd 1 1.140007
32. Albright A, Franz M, Hornsby G, Kriska A, Marrero D, Ullrich I, Verity LS. American College of Sports Medicine position stand. Exercise and type 2 diabetes. Medicine and science in sports and exercise. $2000 \mathrm{Jul}$ 1;32(7):1345-60.

33. Spasi A, Veli R, Cati A, Stefanovi N, Cvetkovi T. Quality of Life in Type 2 Diabetic Patients, 31 (3), 193-200.

34. Diabetes Federation, I. (2019). Idf diabetes atlas 9th adition.

35. Brown CJ, Quah ST, Jong J, Goh AM, Chiam PC, Khoo $\mathrm{KH}$, Choong ML, Lee MA, Yurlova L, Zolghadr K, Joseph TL. Stapled peptides with improved potency and specificity that activate p53. ACS chemical biology. 2013 Mar 15;8(3):506-12.

36. Diabetes Federation, I. (2019). Idf diabetes atlas 9th adition.

37. Aune D, Norat T, Leitzmann M, Tonstad S, Vatten LJ. Physical activity and the risk of type 2 diabetes: a systematic review and dose-response meta-analysis. European journal of epidemiology. 2015 Jul;30(7):52942.

38. Dempsey PC, Larsen RN, Sethi P, Sacre JW, Straznicky NE, Cohen ND, Cerin E, Lambert GW, Owen N, Kingwell BA, Dunstan DW. Benefits for type 2 diabetes of interrupting prolonged sitting with brief bouts of light walking or simple resistance activities. Diabetes care. 2016 Jun 1;39(6):964-72.

39. Bukht MS, Ahmed KR, Hossain S, Masud P, Sultana S, Khanam R. Association between physical activity and diabetic complications among Bangladeshi type 2 diabetic patients. Diabetes \& Metabolic Syndrome: Clinical Research \& Reviews. 2019 Jan 1;13(1):806-9.

40. Alonso-Domínguez R, García-Ortiz L, Patino-Alonso MC, Sánchez-Aguadero N, Gómez-Marcos MA, Recio-Rodríguez Jl. Effectiveness of a multifactorial intervention in increasing adherence to the Mediterranean diet among patients with diabetes mellitus type 2: A controlled and randomized study (EMID Study). Nutrients. 2019 Jan;1 1 (1):162.

41. Fayehun AF, Olowookere OO, Ogunbode AM, Adetunji AA, Esan A. Walking prescription of 10000 steps per day in patients with type 2 diabetes mellitus: a randomised trial in Nigerian general practice. British Journal of General Practice. 2018 Feb 1;68(667):e13945.

42. Sardinha LB, Magalhães JP, Santos DA, Júdice PB. Sedentary patterns, physical activity, and 
cardiorespiratory fitness in association to glycemic control in type 2 diabetes patients. Frontiers in physiology. 2017 Apr 28;8:262.

43. Zhang Y, Pan XF, Chen J, Xia L, Cao A, Zhang Y, Wang J, Li H, Yang K, Guo K, He M. Combined lifestyle factors and risk of incident type 2 diabetes and prognosis among individuals with type 2 diabetes: a systematic review and meta-analysis of prospective cohort studies. Diabetologia. 2020 Jan;63(1):21-33.

44. Alonso-Domínguez R, García-Ortiz L, Patino-Alonso MC, Sánchez-Aguadero N, Gómez-Marcos MA, Recio-Rodríguez Jl. Effectiveness of a multifactorial intervention in increasing adherence to the Mediterranean diet among patients with diabetes mellitus type 2: A controlled and randomized study (EMID Study). Nutrients. 2019 Jan;1 1 (1):162.

45. Bukht MS, Ahmed KR, Hossain S, Masud P, Sultana S, Khanam R. Association between physical activity and diabetic complications among Bangladeshi type 2 diabetic patients. Diabetes \& Metabolic Syndrome: Clinical Research \& Reviews. 2019 Jan 1;13(1):806-9.

46. Fayehun AF, Olowookere OO, Ogunbode AM, Adetuniji AA, Esan A. Walking prescription of 10000 steps per day in patients with type 2 diabetes mellitus: a randomised trial in Nigerian general practice. British Journal of General Practice. 2018 Feb 1;68(667):e13945.

47. Gautret P, Lagier JC, Parola P, Meddeb L, Mailhe M, Doudier B, Courjon J, Giordanengo V, Vieira VE, Dupont HT, Honoré S. Hydroxychloroquine and azithromycin as a treatment of COVID-19: results of an open-label non-randomized clinical trial. International journal of antimicrobial agents. $2020 \mathrm{Jul}$ 1:56(1):105949.

48. Krejcie RV, Morgan DW. Determining sample size for research activities. Educational and psychological measurement. 1970 Sep;30(3):607-10.

49. Fisher L, Mullan JT, Arean P, Glasgow RE, Hessler D, Masharani U. Diabetes distress but not clinical depression or depressive symptoms is associated with glycemic control in both cross-sectional and longitudinal analyses. Diabetes care. 2010 Jan 1;33(1):23-8.

50. Burroughs TE, Desikan R, Waterman BM, Gilin D, McGill J. Development and validation of the diabetes quality of life brief clinical inventory. Diabetes Spectrum. 2004 Jan 1;17(1):41-9.
51. Çolak TK, Acar G, Dereli EE, Özgül B, Demirbüken I, Alkaç Ç, Polat MG. Association between the physical activity level and the quality of life of patients with type 2 diabetes mellitus. Journal of physical therapy science. 2015;28(1):142-7.

52. Bassuk SS, Manson JE. Epidemiological evidence for the role of physical activity in reducing risk of type 2 diabetes and cardiovascular disease. Journal of applied physiology. 2005 Sep 1.

53. Gill JM, Cooper AR. Physical activity and prevention of type 2 diabetes mellitus. Sports Medicine. 2008 Oct;38(10):807-24.

54. Hu G, Lakka TA, Barengo NC, Tuomilehto J. Physical activity, physical fitness, and risk of type 2 diabetes mellitus. Metabolic syndrome and related disorders. 2005 Mar 1;3(1):35-44.

55. Hamasaki H. Daily physical activity and type 2 diabetes: A review. World journal of diabetes. 2016 Jun 25;7(12):243.

56. Colberg SR, Sigal RJ, Fernhall B, Regensteiner JG, Blissmer BJ, Rubin RR, Chasan-Taber L, Albright AL, Braun B. Exercise and type 2 diabetes: the American College of Sports Medicine and the American Diabetes Association: joint position statement. Diabetes care. 2010 Dec 1;33(12):e147-67.

57. Advika TS, Idiculla J, Kumari SJ. Exercise in patients with Type 2 diabetes: Facilitators and barriers-A qualitative study. Journal of family medicine and primary care. 2017 Apr;6(2):288.

58. Colberg SR, Sigal RJ, Yardley JE, Riddell MC, Dunstan DW, Dempsey PC, Horton ES, Castorino K, Tate DF. Physical activity/exercise and diabetes: a position statement of the American Diabetes Association. Diabetes care. 2016 Nov 1:39(11):2065-79. 